\title{
Mesh erosion following prosthetic hiatal closure
}

\author{
F. A. Granderath $\cdot$ R. Pointner
}

Received: 19 October 2007 / Accepted: 19 October 2007/Published online: 11 December 2007

(C) Springer Science+Business Media, LLC 2007

Keywords GORD/GERD - Surgical technique · Hiatal closure

We appreciate the interest of Dr. Vakili in our recently published study "Laparoscopic antireflux surgery: Tailoring the hiatal closure to the size of hiatal surface area" [1]. The main objective of the article was to present a standardized technique of measuring the hiatal defect during laparoscopic antireflux surgery and large hiatal hernia repair [2] and subsequently find an appropriate way to effectively close the hiatal defect. We are aware that the use of prosthetic materials for crural closure can lead to postoperative mesh-related complications such as mesh erosion or mesh migration into the distal esophagus or the stomach. Because of these complications, we must have a standardized technique for effectively closing the esophageal hiatus with low recurrence rates on the one hand and a minimization of mesh-related complications on the other hand. Like Dr. Vakili, we believe that the routine use of prosthetic meshes or pledgets for hiatal closure during laparoscopic antireflux procedures must be srutinized.
Dr. Vakili also reported on two patients who returned with esophageal erosion from hiatal closure with polypropylene pledgets. A large number of studies show that there is a high recurrence rate in patients with large hiatal or paraesophageal hernias [3]. An efficient closure of the hiatus often is impossible in these patients without the use of mesh. To strike a balance between these positions, the use of mesh should depend on the size of the hiatal defect [2].

\section{References}

1. Vakili C (2007) Laparoscopic antireflux surgery: Tailoring the hiatal closure to the size of the hiatal area. Surg Endosc 21:1900 [Letter]

2. Granderath FA, Schweiger UM, Pointner R (2007) Laparoscopic antireflux surgery: tailoring the hiatal closure to the size of hiatal surface area. Surg Endosc 21:542-548

3. Hashemi M, Peters JH, DeMeester TR, Huprich JE, Quek M, Hagen JA, Crookes PF, Theisen J, DeMeester SR, Sillin LF, Bremner CG (2000) Laparoscopic repair of large type III hiatal hernia: objective followup reveals high recurrence rate. J Am Coll Surg 190(5):553-560

F. A. Granderath $(\bowtie)$

Department of General, Visceral and Transplant Surgery,

University Hospital of Tuebingen, Hoppe - Seyler - Strasse 3,

D72076 Tuebingen, Germany

e-mail: frank.granderath@med.uni-tuebingen.de

R. Pointner

Department of General Surgery, Hospital Zell am See,

5700 Zell am See, Austria 